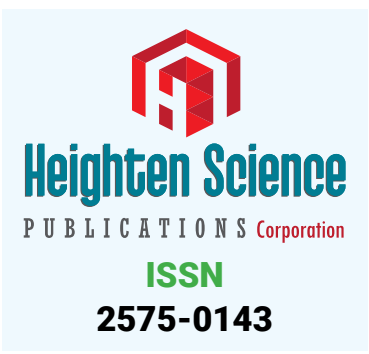

*Address for Correspondence: Kenneth T. Moore, M.S, Scientific Director, Cardiovascular Disease, Janssen Pharmaceuticals, Inc., 1125 Trenton-Harbourton Road, Titusville, NJ 08560, USA, Tel: (609) 730-6452; C\# (732) 822-9754; Email:Tmoore17@its.jnj.com

Submitted: 26 September 2018 Approved: 10 October 2018 Published: 11 October 2018

Copyright: (c) 2018 Moore KT, et al. This is an open access article distributed under the Creative Commons Attribution License, which permits unrestricted use, distribution, and reproduction in any medium, provided the original work is properly cited.

Keywords: Renal Impairment; Rivaroxaban; Apixaban

Check for updates
Opinion

\section{Use of Rivaroxaban and Apixaban, Two Non-Vitamin K Antagonist Oral Anticoagulants (NOACs), in Renally Impaired Patients - the limits of our knowledge}

\author{
Kenneth T Moore* and Maria Langas \\ Cardiovascular Disease, Janssen Pharmaceuticals, Inc., Titusville, NJ 08560, USA
}

Patients with chronic kidney disease are at increased risk of thromboembolic complications and are therefore often managed with anticoagulation therapy [1]. While these patients are traditionally treated with Vitamin $\mathrm{K}$ antagonists (VKAs), the NonVitamin K antagonist oral anticoagulants (NOACs), such as rivaroxaban and apixaban are being used with increasing frequency. Relatively new to the anticoagulant treatment arsenal, both compounds are direct Factor Xa inhibitors and represent an alternative to traditional VKA treatments, such as warfarin. However, because these compounds are at least partially renally eliminated, achieving safe and effective anticoagulation in this vulnerable population has proven to be a challenge [2,3]. With limited published data, there is often uncertainty surrounding which of the NOACs can be safely used.

What can we do to address this issue? To start, those involved in drug development need to enhance their efforts to recruit renally impaired patients within their pivotal clinical trials. The sponsors of the four available NOACs attempted to capture this population in their recent Phase 3 studies, ROCKET-AF (rivaroxaban), ARISTOTLE (apixaban), RE-LY (dabigatran), and ENGAGE AF-TIMI (edoxaban), which all included patients with varying degrees of renal insufficiency [4-7]. The ROCKET-AF trial stands out in its attempt to lessen this data gap by recruiting 2,950 patients with a creatinine clearance $(\mathrm{CrCl}$ ) of $<30$ to $49 \mathrm{ml} / \mathrm{min}$, thus accounting for approximately $21 \%$ of the total ROCKET-AF population [4]. While this relatively high enrollment number informs on efficacy and safety in this patient subgroup, there remains a need for additional data. Although pharmacology data are available for both dabigatran and edoxaban, the purpose of this commentary is to provide an understanding of what data exist and support treatment direction in the respective labels for rivaroxaban and apixaban.

To understand the influence of renal function on NOAC use, apixaban and rivaroxaban pharmacokinetics (PK) and pharmacodynamics (PD) were evaluated in otherwise healthy subjects with mild, moderate, or severe renal impairment in similarly designed clinical pharmacology trials. Both were open-label, parallel group, multi-center, studies that included 32 subjects (24 with different degrees of renal function and 8 healthy controls). Subjects were divided into four groups based on their level of renal function, determined by $\mathrm{CrCl}$ level: healthy controls $(\mathrm{CrCl}>80 \mathrm{ml} /$ min), mild impairment ( $\mathrm{CrCl} 50-79 \mathrm{ml} / \mathrm{min}$ [rivaroxaban], $\mathrm{CrCl}>50$ and $<80 \mathrm{ml} / \mathrm{min}$ [apixaban]), moderate impairment (30-49 $\mathrm{ml} / \mathrm{min}$ [rivaroxaban], $\mathrm{CrCl}>30-<50 \mathrm{ml} /$ min [apixaban]), and severe impairment $(\mathrm{CrCl}<30$ and not on dialysis). Under fasting 
conditions, subjects received either a single dose of rivaroxaban $10 \mathrm{mg}$ or apixaban 10 $\mathrm{mg}$ in their respective trials. Serial blood and urine samples were collected throughout the trials for PK and PD assessments [8,9].

In both studies systemic exposure, measured by area under the concentration-time curve (AUC), increased similarly as $\mathrm{CrCl}$ decreased or renal function worsened. Apixaban displayed a 16\%, 29\%, and 38\% increase in AUC for those subjects with mild, moderate, and severe renal impairment, respectively [8]. In a similar pattern, rivaroxaban displayed a 44\%, 52\%, and 64\% increase in AUC for those subjects with mild, moderate, and severe renal impairment, respectively [7]. These AUC values can be seen in table 1. This increase in systemic exposure was expected, as there is a decrease in overall drug clearance as renal function deteriorates. These clinical pharmacology data in turn complement the limited safety and efficacy data obtained in the phase 3 clinical trials.

The only data available for rivaroxaban and apixaban in patients with End Stage Renal Disease (ESRD: $\mathrm{CrCl}<15 \mathrm{ml} / \mathrm{min}$ ) and on dialysis are strictly from clinical pharmacology studies. Both sponsors conducted a similarly designed trial which consisted of an open-label, parallel group, single center design. In each study, 16 otherwise healthy subjects were enrolled, eight with ESRD and on dialysis and eight with normal renal function. All subjects were administered a single dose of medication, either rivaroxaban $15 \mathrm{mg}$ or apixaban $5 \mathrm{mg}$. Patients with normal renal function received a single dose once and patients with ESRD received a single dose twice (once prior to dialysis and once after dialysis), separated by a washout period. Serial PK and PD blood samples were collected prior to dose and up to 72 hours post-dose in both studies. The only significant deviation between the two study designs was the use of saline or low-dose unfractionated heparin during dialysis to keep the lines patent for patients receiving apixaban or rivaroxaban, respectively $[10,11]$.

Once again, both studies yielded a similar pattern in results. The overall increase in systemic exposure post-dialysis, as measured AUC was $36 \%$ for apixaban and $56 \%$ for rivaroxaban $[10,11]$. These AUC values are also depicted in table 1 . Both compounds show a potential maximum increase in systemic exposure once a patient reaches a level of moderate to severe renal impairment.

Based on the totality of the data on renally impaired subjects, the US Food and Drug Administration went through a process of label harmonization regarding the renally impaired Atrial Fibrillation (AF) population. The result is that both the apixaban and rivaroxaban labels have nearly identical recommendations for patients with renal impairment or ESRD on dialysis and AF. These recommendations can be found in section 8.6 of the respective labels [2,3] (Table 2). It is important to understand that although both compounds have a recommended dosing for patients with ESRD and AF, neither has an FDA approved indication for use in this population. Both labels indicate, "It is not known whether these concentrations will lead to similar stroke reduction and bleed risk in patients with ESRD on dialysis as was seen in ROCKET-AF/ARISTOTLE," respectively, which is based on this limited PK and PD data [2,3].

While data are limited in the renal population with AF, rivaroxaban and apixaban share nearly identical FDA labeling and recommendations. Physicians should be informed of their options and these limitations. As Sponsors of these trials, the pharmaceutical industry needs to continue its efforts to obtain data in these 'real world' types of patients. After all, "The level of our success is limited only by our imagination and no act of kindness, however small, is ever wasted". (Aesop).

Table 1: Rivaroxaban and apixaban systemic exposure (AUC).

\begin{tabular}{|c|c|c|}
\hline Renal Impairment & Rivaroxaban AUC Increase & Apixaban AUC Increase \\
\hline Mild & $44 \%$ & $16 \%$ \\
\hline Moderate & $52 \%$ & $29 \%$ \\
\hline Severe & $64 \%$ & $38 \%$ \\
\hline ESRD on Dialysis & $56 \%$ & $36 \%$ \\
\hline
\end{tabular}


Table 2: Section 8.6 "Patients with End-Stage Renal Disease on Dialysis" of rivaroxaban and apixaban labels [2,3] Rivaroxaban Apixaban

Clinical efficacy and safety studies with XARELTO did not Clinical efficacy and safety studies with ELIQUIS did not enroll patients with end-stage renal disease (ESRD) on enroll patients with end-stage renal disease (ESRD) on dialysis. In patients with ESRD maintained on intermittent dialysis. In patients with ESRD maintained on intermittent hemodialysis, administration of XARELTO $15 \mathrm{mg}$ once hemodialysis, administration of ELIQUIS at the usually daily will result in concentrations of rivaroxaban and recommended dose [see Dosage and Administration pharmacodynamic activity similar to those observed in the (2.1)] will result in concentrations of apixaban and ROCKET-AF study [see Clinical Pharmacology $(12.2,12.3)$ ]. pharmacodynamic activity similar to those observed in It is not known whether these concentrations will lead to the ARISTOTLE study [see Clinical Pharmacology (12.3)]. similar stroke reduction and bleeding risk in patients with It is not known whether these concentrations will lead to ESRD on dialysis as was seen in ROCKET AF. similar stroke reduction and bleeding risk in patients with ESRD on dialysis as was seen in ARISTOTLE.

\section{References}

1. Lutz J, Jurk K, Schinzel H. Direct oral anticoagulants in patients with chronic kidney disease: patient selection and special considerations. Int J Nephrol Renovasc Dis. 2017; 10: 135-143. Ref.: https://goo.gl/MBu8sA

2. Xarelto [package insert]. Raritan, NJ. Janssen Pharmaceutical Companies. 2011 (revised October 2017).

3. Eliquis [package insert]. Princeton, NJ: Bristol-Myers Squibb Company. 2012 (revised February 2018).

4. Patel MR, Mahaffey KW, Garg J, Pan G, Singer DE, et al. Rivaroxaban versus warfarin in nonvalvular atrial fibrillation. N Engl J Med. 2011; 365: 883-891. Ref.: https://goo.gl/JZux9g

5. Granger $\mathrm{CB}$, Alexander $\mathrm{JH}$, McMurray JJ, Lopes RD, Hylek EM, et al. Apixaban versus warfarin in patients with atrial fibrillation. N Engl J Med. 2011; 365: 981-992. Ref.: https://goo.gl/vuXaQr

6. Connolly SJ, Ezekowitz MD, Yusuf S, Eikelboom J, Oldgren J, et al. Dabigatran versus Warfarin in Patients with Atrial Fibrillation. N Engl J Med. 2009; 361: 1139-1151. Ref.: https://goo.gl/fs8ha2

7. Giugliano RP, Ruff CT, Braunwald E, Murphy SA, Wiviott SD, et al. Edoxaban versus Warfarin in Patients with Atrial Fibrillation. N Engl J Med. 2013; 369: 2093-2104. Ref.: https://goo.gl/XXRm3h

8. Kubitza D, Becka M, Mueck W, Halabi A, Maatouk $H$, et al. Effects of renal impairment on the pharmacokinetics, pharmacodynamics and safety of rivaroxaban, an oral, direct factor Xa inhibitor. Br J Clin Pharmacol. 2010; 70: 703-712. Ref.: https://goo.gl/uENJM7

9. Chang M, Yu Z, Shenker A, Wang J, Pursley J, et al. Effect of renal impairment on the pharmacokinetics pharmacodynamics, and safety of apixaban. J Clin Pharmacol. 2010; 56: 637-645. Ref.: https://goo.gl/Ukqwgs

10. Dias C, Moore KT, Murphy J, Ariyawansa J, Smith W, et al. Pharmacokinetics, pharmacodynamics, and safety of single-dose rivaroxaban in chronic hemodialysis. Am J Nephrol. 2016; 43: 229-236. Ref.: https://goo.gl/2kb1sU

11. Wang X, Tirucherai G, Marbury TC, Wang J, Chang M, et al. Pharmacokinetics, pharmacodynamics, and safety of apixaban in subjects with end-stage renal disease on hemodialysis. J Clin Pharmacol. 2016; 56: 628-636. Ref.: https://goo.gl/3Jrgm4 